\title{
Acquisition of Offshore Engineering Design Skills on Naval Architecture Master Courses Through Potential Flow CFD Tools
}

\author{
JOSÉ E. GUTIÉRREZ-ROMERO, ${ }^{1}$ BLAS ZAMORA-PARRA, ${ }^{2}$ IERÓNIMO A. ESTEVE-PÉREZ1 \\ ${ }^{1}$ Department of Naval Technology, Universidad Politécnica de Cartagena, Paseo Alfonso XIII 52, Cartagena 30203, Spain \\ ${ }^{2}$ Department of Thermal and Fluids Engineering, Universidad Politécnica de Cartagena, Doctor Fleming s/n, Cartagena \\ 30202, Spain
}

Received 27 July 2016; accepted 19 October 2016

\begin{abstract}
This paper presents a teaching-learning methodology focused on the acquisition of basic design principles in offshore engineering for a course entitled Projects in Offshore Maritime Structures, in a Master of Naval Architecture and Ocean Engineering. A new teaching procedure (including the Project-Based Learning approach), is proposed, for ensuring that students acquire skills related to the ability of analyzing and designing ocean structures. The roles of the Information and Communication Technologies, Computational Fluid Dynamics, potential flow methods and structural analysis are some specific features of the proposed methodology. The method increases the satisfaction of the students in a significant manner, and opens their fields in research and development on offshore engineering. (c) 2016 Wiley Periodicals, Inc. Comput Appl Eng Educ; View this article online at wileyonlinelibrary.com/journal/cae; DOI 10.1002/cae.21778
\end{abstract}

Keywords: project-based learning; Naval Architecture and Ocean Engineering; computational fluid dynamics; information technologies

\section{INTRODUCTION}

\section{Marine and Offshore Engineering. Educational Overview}

In the past, design and operation of ships and offshore structures have been based mainly on the experience, including a traditional treatment. Today, this is still the case to some extent, but the clear advantages of the virtual experience [1] and the numerical simulation are causing a radical change in the field of Naval Architecture and Ocean Technology [2].

Since improving education has received so far only a limited attention on the Maritime and Offshore Industries, this paper

Correspondence to B. Zamora-Parra (blas.zamora@upct.es).

(c) 2016 Wiley Periodicals, Inc. describes a teaching-learning methodology focused on the acquisition of basic design skills on offshore engineering for the course Projects in Offshore Maritime Structures in the Master of Naval Architecture and Ocean Engineering at the Technical University of Cartagena. Aiming the improvement of the teachinglearning process, a pedagogical method based on the use of Information and Communication Technologies (ICT) assisted with Computational Fluid Dynamics (CFD) techniques is implemented. It is well known that the visualization and understanding of the flow pattern are critical objectives, which can be achieved using numerical simulation techniques [3,4]. In fact, CFD techniques are employed in topics concerning with shape hull optimization for reducing resistance and powering in Marine Engineering [5,6], with the offshore industry applications [2], or for instance, with the response analysis of moored floating structures using tools such as the Potential Flow Solver (PFS) and the non-linear Finite Element Method (FEM) approach [7]. 
Regarding the student learning, the Marine Engineering graduates should be well oriented to problem solving for difficult situations. In fact, a marine professional has to be able to take the appropriate decisions under critical and emergency phenomena, especially in the offshore industry applications, in which multidisciplinary knowledge is mandatory in order to carry out the right actuations. In this context, the Problem-Based Learning $(P B L)$ approach for educational procedures plays an important role in the aspects of motivation in students of Marine Engineering, and therefore it is the approach adopted in present work.

\section{CFD, Computers, and ICT Tools}

The use of computational software packages for solving the equations of the fluid motion, that is, CFD [8], can constitute a powerful hand-on designed to improve the learning process of the students. It is clear that this tool must not be used as a black box; indeed, it should be employed to analyze carefully the physical meaning of the input data (boundary and initial conditions) and the obtained results (contours of relevant magnitudes such as pressure, velocity, ...), as well as overall parameters related to ship and offshore structures design [9]. Moreover, in general, the students appreciate the use of computers and numerical techniques for solving engineering problems [10]. In this paper, the application of CFD as a teaching-learning tool in order to improve engineering education [11,12] is an essential component of the applied methodology. It can be expected that the use of CFD tools give students a better understanding in any field of Engineering [13], and specifically in the design of new ships or offshore structures.

Online Learning and ICT tools have been applied on several Engineering fields. Panagiotopoulos and Manolis, for instance, presented a web-based educational software for structural dynamics [14]. In Marine Engineering and Naval Architecture, it can be cited the works of [15] or [16], for research or professional purposes, and $[17,18]$, for educational purposes, being delivered with Virtual Learning Environment (VLE). CAD computer software or EES ${ }^{\circledR}$ (Engineering Equation Solver), or programming languages such as Matlab ${ }^{\circledR}$ or Visual Basic ${ }^{\circledR}$, among others, have been used in Marine Engineering education. The advantage of using VLE is that it provides tracking facilities so that the tutor can obtain information from students, activities done or the documents they have accessed. In addition, different technologies and methods for developing virtual campus have appeared in recent years; a tool as Camtasia Studio ${ }^{\circledR}$ Software [19] can be employed for customizing screen recordings, video with software demos, or creating interactive videos, for instance. Irrespective of the presence of a virtual campus, these utilities can be successfully applied to classical methods for teaching and learning [9].

\section{The Aim of This Work}

This paper is concerned with a teaching experience and pedagogical method applied on the course Projects in Offshore Maritime Structures in the Master of Naval Architecture and Ocean Engineering, as explained above. The ongoing pedagogical method deals with the blended learning, which is based on a combination of face-to-face environment and online learning, including the Problem-Based Learning and mainly focused on the Project-Based Learning approach using CFD tool, as well as the supervised learning as a key element of the educational process.
Following the PBL approach [20,21], several stages in which numerical simulation projects are the base have been performed, with the aim of the assessment of learning achieved by the student.

The applied methodology is based on specific projects proposed to graduates. As explained below, the methodology is divided into several steps concerning with different topics of offshore structure projects, from knowledge of ocean environment to estimation the dynamic behavior of floating offshore units. As mentioned before, the use of CFD tool constitutes an important part of learning operational process. The employed CFD code, SeaFEM [22] developed by the CompassIS Company is a suite of tools for the computational analysis of the effect of waves, wind, and currents on naval and offshore structures, as well as for maneuvering studies. This tool solves the multi-body radiation and diffraction problem, by using potential flow equations in the time domain, through the finite element method on unstructured meshes.

Summarily, teaching a software engineering course should be balanced between theory and practice. So, the merge of Information and Communication Technologies (ICT) and the Potential Flow Solver (PFS) SeaFEM, generates a large number of possibilities in improving and deepening basic and advanced aspects related to the offshore design.

\section{PEDAGOGICAL METHOD}

\section{General Guidelines}

The presented methodology is applied from the beginning of the subject Projects in Offshore Maritime Structures of the Master above mentioned. The syllabus of the subject is divided into the following four parts: (I) Introduction and classification of offshore structures. (II) Basics of offshore structure design. (III) Offshore equipment and technology. (IV) Construction, installation, and operation.

The applied methodology is mainly concerned with parts I, II, and III. These parts of syllabus include the study of different types of offshore structures, the analysis of metocean conditions, the study of environmental forces in offshore units, the consideration of structural requirements in offshore design, the study of permanents mooring in floating structures, the analysis and description of the equipment and processes in offshore structures and the study of the stages in construction, installation, and operation of offshore structures. As relevant hands-on learning tools, the portfolio is used to limit the bibliographical sources, and to clarify the learning progress of the graduates. The use of conceptual maps is proposed to correct the knowledge deficiencies in some aspects related to Structural and Fluid Mechanics, which are necessary to understand the wavestructure interaction and the basics of structural analysis and the application of Load and Resistance Factor Design (LRDF) method.

It should be noted that the aim of this engineering process is focused on stimulation of modeling and research in offshore structures. As a relevant advantage, the CFD tool reveals itself as profitable hands-on tool that can be used in the regarded pedagogical method. Keeping in mind that the misunderstanding of the numerical results by students may be damaging to their academic and professional education, special attention is posed to the appropriate interpretation of the physical meaning of results, as it is presented below through comparison between numerical and analytical results in different simulations. 


\section{The Project-Based Learning Approach}

The Problem-Based Learning and the Project-Based Learning (PBL) can be considered as methodological approaches in which learners solve problems (or projects) of varying degrees of complexity, employing resources that they think may be suitable. PBL methods were developed in the Medicine fields from the pioneer's works of Professor Howard S. Burrows et al. However, its implementation in the Engineering has been somewhat slower, because of difficulties inherent to training in technical sciences such as no easy subjects to teach and learn, or the necessary knowledge of the physical principles that they demand, among others [23]. In this manner, although careful and detailed planning and organization by the teacher are required, the implementation of its strategies in the classroom has numerous benefits, including a greater depth of understanding of concepts, broader knowledge base, improved communication, and skills (leadership, creativity, writing full, and comprehensive reports...).

Thomas Markham briefly describes Project-Based Learning (PBL) as follows "PBL integrates knowing and doing. Students learn knowledge and elements of the core curriculum, but also apply what they know to solve authentic problems and produce results that matter" [21]. In this sense, it is mandatory to enhance the figure of John Dewey, who generated a unique impact on Education [24]. In fact, from original concepts introduced by Dewey such as the reflective thinking, several authors have studied and developed the idea of reflective learning [25,26], among others. Moreover, Dewey initially promoted the idea of learning by doing and then educational research advanced this idea of teaching and learning into the methodology known as ProjectBased Learning.

In the field of question, a literature survey reveals that several authors claim that PBL procedures should be well established as an essential objective for the Marine Engineering Education [9]. Mora-Luis et al. carried out a research on the PBL approach in
Marine Engineering Education using mobile devices and internet tools [27], and [28] explained the appropriateness of PBL in Maritime Education and training.

\section{LEARNING OPERATIONAL STAGES}

The learning process merges the theory classes with the practice; it is divided into five stages, which are necessarily consecutives. Figure 1 shows the stages concerned with the acquisition of skills related to offshore hydromechanics analysis and design. Five steps are established in a progressive learning process from environmental conditions to dynamic behavior of floating structures. Each stage of learning process may be considered as a representative key problem on offshore engineering design. The steps are:

- Stage 1: Knowledge about the metocean conditions in offshore design.

- Stage 2: Estimation of the environmental forces on offshore units.

- Stage 3: Description and analysis of offshore equipment.

- Stage 4: Analysis of position mooring in floating offshore units.

- Stage 5: Dynamic analysis of floating offshore units under several metocean conditions.

\section{First Stage}

First learning stage is based on acquisition of basic skill of wave environment studied in regular classes. The student should create a numeric wave tank. Then, the graduates will be able to simulate different sea states using different wave theories: regular wave and irregular wave using JONSWAP or Pearson-Moskowitz (PM) spectrums $[29,30]$. The sea spectrum PM is one of the most

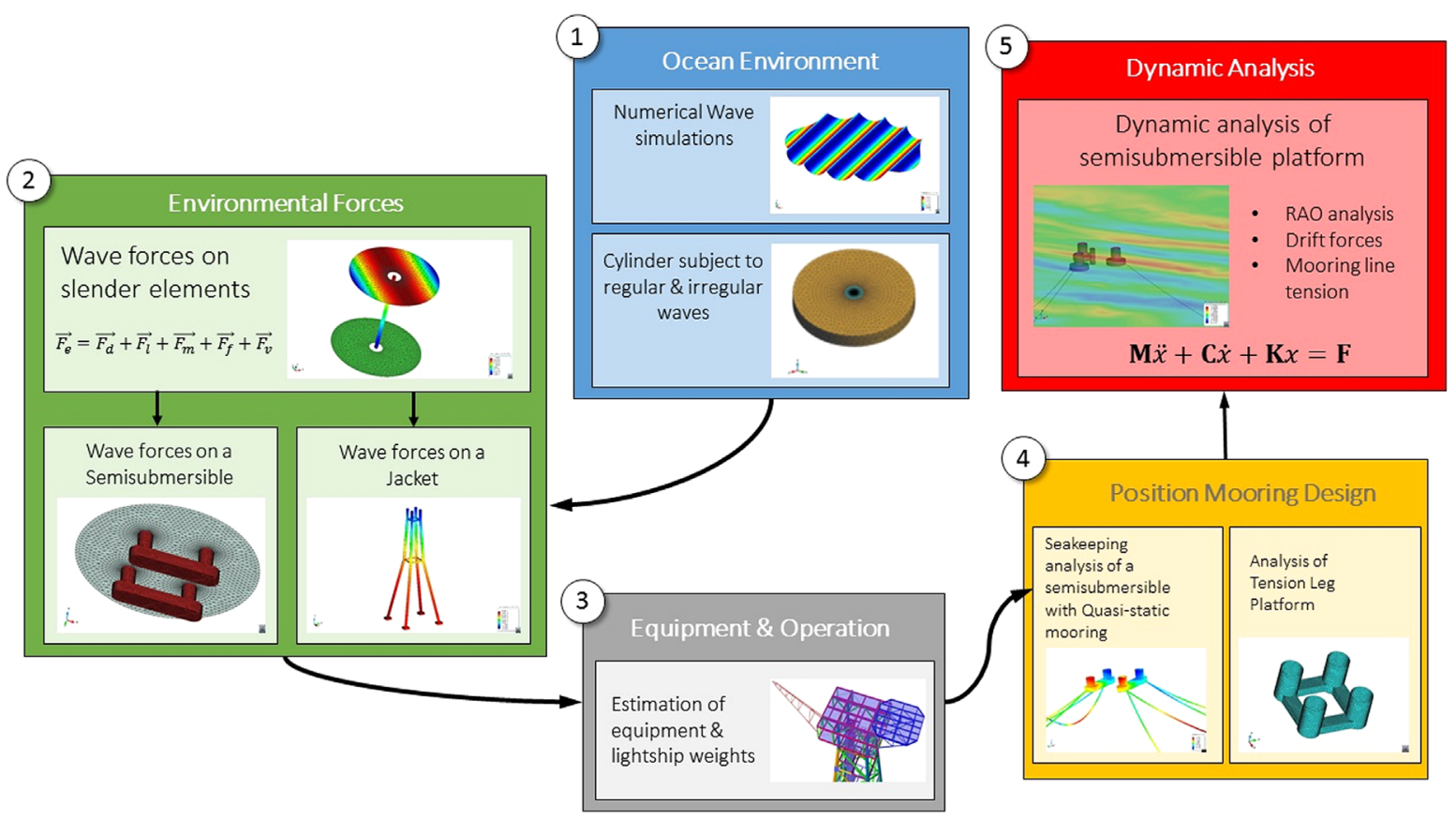

Figure 1 Adopted scheme for the project-based learning for the course Projects in Offshore Maritime Structures. 
popular in the offshore technology, mainly suitable for the North Sea. The PM spectrum $S(w)$ is given by the following equation, depending on the site where the floating units are placed,

$$
S(\omega)=\frac{\alpha g^{2}}{\omega^{5}} \exp \left[-\beta\left(\frac{\omega}{\omega_{0}}\right)^{-4}\right]
$$

where $\alpha$ is the Phillip constant, $g$ is the gravity acceleration, $\omega$ is the wave frequency, $\beta$ is a constant and $\omega_{0}$ is the modal frequency.

This basis stage helps the student to know the basic options of Potential Flow Solver (PFS) used on next steps, the different strategies to carry out the numerical simulations, etc. Video tutorials focused on presenting the available options of PFS are made. So, the use of ICT as video tutorial makes faster the process learning of the student. Figure 2 shows two simulated sea states on the numerical wave tank using PFS. Each graduate has to analyze and process the approximation to the sea state created by PFS.

\section{Second Stage}

The main objective of the second learning stage is focused on the understanding of how the environmental forces act on ocean structures. Two sub-stages are proposed to tackle the two hypothesis used on the hydromechanical analysis of offshore structures [31,32]. The first hypothesis consists of the consideration of the offshore unit as a hydrodynamically transparent structure, as typical of jacket structures, and the second one is the consideration of the platform as a hydrodynamically compact structure, as semi-submersible platforms. First, the graduates study the actions of the wind, current, and wave forces on offshore structures. Through different proposed exercises and the use of PFS solver, the students have to overcome the learning difficulties about how the environmental forces act (see Fig. 1).

As previous stage, the project-based learning is used for the acquisition of the skills related to hydromechamical analysis of
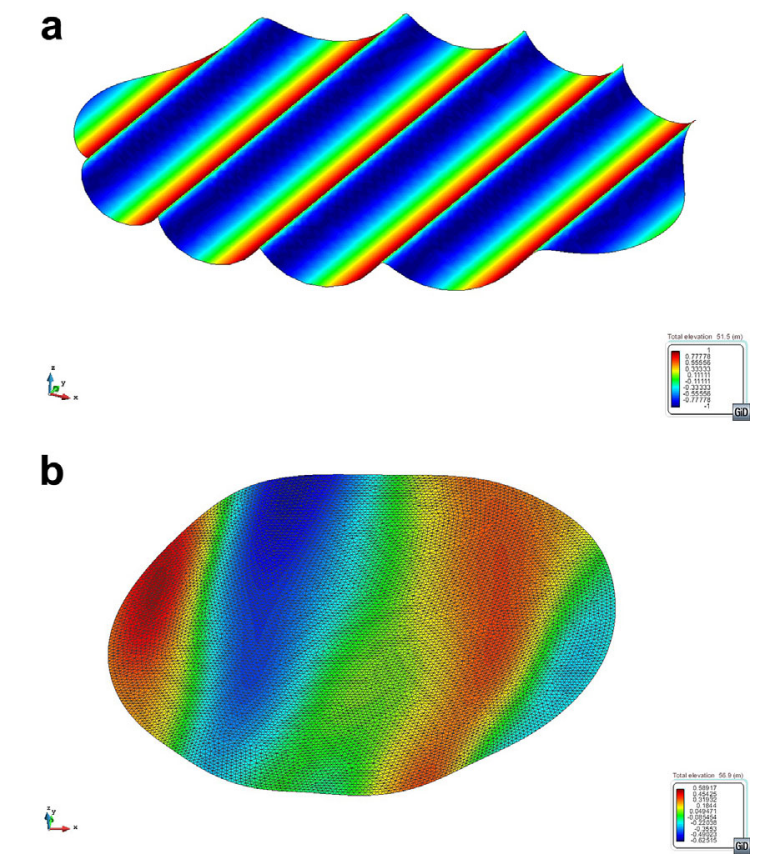

Figure 2 Obtained free surface on numerical wave tank. (a) From the simulation of regular waves. (b) From the simulation of irregular waves. offshore structures. To introduce the student in the hydromechanical study of offshore structures, first wave forces acting on vertical pile are studied by using direct numerical calculation and the Potential Flow Solver (see Figs. 3 and 4). The estimation of wave forces on vertical piles may be considered as a previous step of the hydromechanical analysis of jacket structure. In this direction, when viscous effects may be advanced to have a significant effect on the dynamic behavior of an offshore structure, the Morison's equation can be used to evaluate wave loads on slender elements of the structure [31-33]. It is useful to write the Morison's equations in a vectorial formulation that automatically takes into account the actual orientation of structural elements and force components. Considering a segment of a long slender structural element submerged into water, its local orientation is given by a unit vector,

$$
\mathbf{t}=l \mathbf{i}+m \mathbf{j}+n \mathbf{k}
$$

where $l, m$, and $n$ are the directional cosines.

Then, the forces per unit length on a slender cylindrical element may be written as the sum of inertia, drag, friction, and lift forces [22]:

$$
\boldsymbol{F}_{\mathrm{sl}}=\boldsymbol{F}_{m}+\boldsymbol{F}_{d}+\boldsymbol{F}_{v}+\boldsymbol{F}_{f}+\boldsymbol{F}_{l}
$$

being $\boldsymbol{F}_{m}$ the inertia forces, $\boldsymbol{F}_{d}$ the drag forces, $\boldsymbol{F}_{v}$ the viscous forces, $\boldsymbol{F}_{f}$ the friction forces along the axis, and $\boldsymbol{F}_{l}$ the lift forces on slender elements. Thus, the total forces are

$$
\begin{gathered}
\boldsymbol{F}_{m}=\left(1+C_{m}\right) \rho \mathrm{S}(\boldsymbol{t} \times \ddot{\boldsymbol{x}} \times \boldsymbol{t}) \\
\boldsymbol{F}_{d}=0,5 C_{d} \rho D(\boldsymbol{t} \times \dot{\boldsymbol{x}} \times \boldsymbol{t})|\boldsymbol{t} \times \dot{\boldsymbol{x}} \times \boldsymbol{t}| \\
\boldsymbol{F}_{v}=0,5 C_{v} \rho D(\boldsymbol{t} \times \dot{\boldsymbol{x}} \times \boldsymbol{t}) \\
\boldsymbol{F}_{f}=0,5 C_{f} \rho \pi D|\boldsymbol{t} \cdot \dot{\boldsymbol{x}}|(\boldsymbol{t} \cdot \dot{\boldsymbol{x}}) \cdot \boldsymbol{t} \\
\boldsymbol{F}_{l}=0,5 C_{l} \rho D|\boldsymbol{t} \times \dot{\boldsymbol{x}}|(\boldsymbol{t} \times \dot{\boldsymbol{x}})
\end{gathered}
$$

where $C_{M}, C_{d}, C_{v}, C_{f}$, and $C_{l}$ are the inertia, the drag, the viscous, the friction and the lift coefficient, respectively. The variable $\mathrm{D}$ is the diameter of the slender element, $\rho$ is the fluid density and $\dot{x}$ and $\dot{x}$ are the first and the second derivatives of the displacement vector.

When the students have analyzed the forces on vertical pile, the second step in project-based learning, the analysis of a jacket structure, is performed. In this step, the graduates have to model a jacket structure as it is presented in Figure 5. The use of ICT tools may help them to overcome the difficulties of jacket modeling.

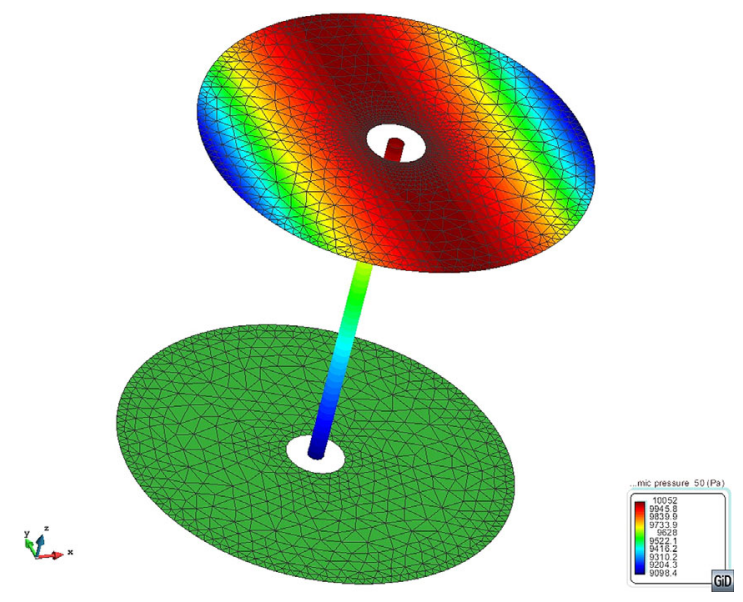

Figure 3 Caption resulting from simulation of the impact of regular waves on vertical pile. 


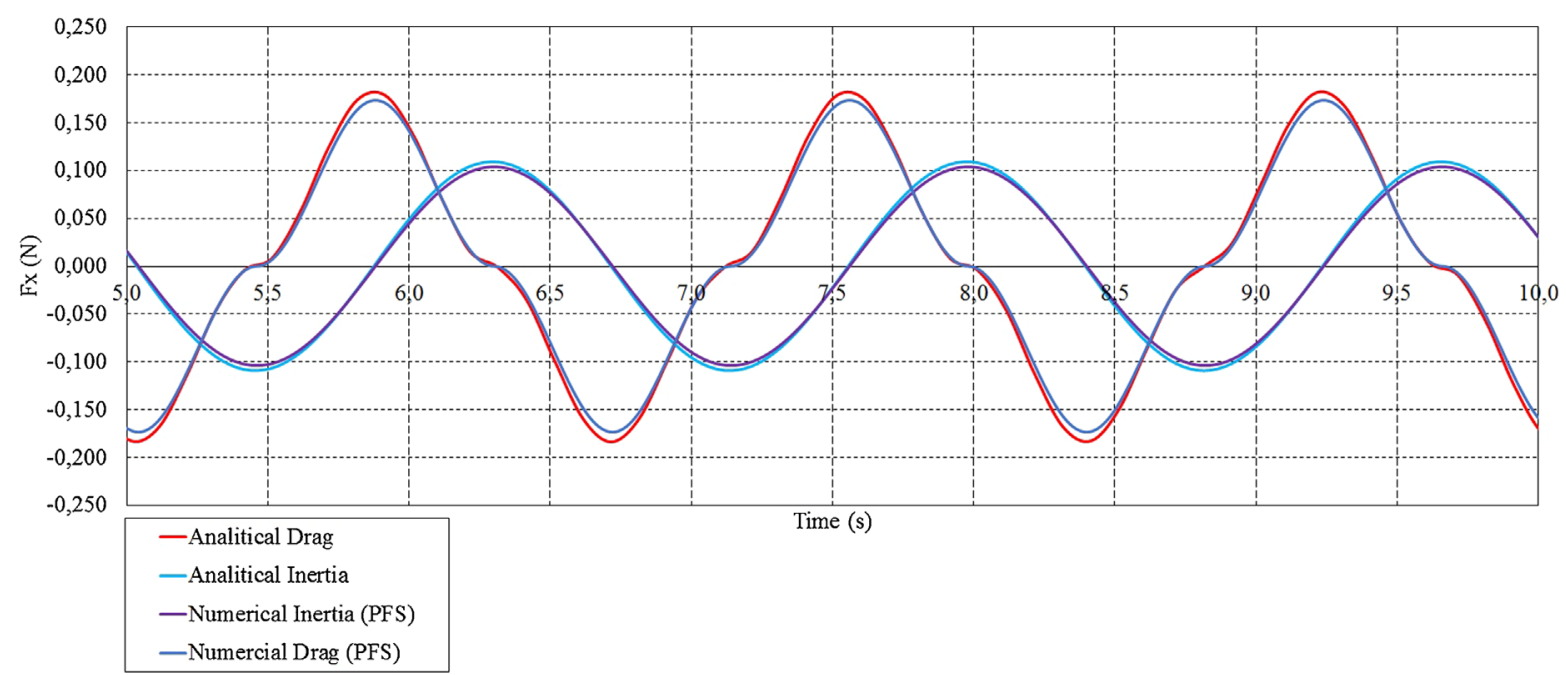

Figure 4 Comparison between analytical and numerical results of forces on vertical pile subject to regular waves obtained with Potential Flow Solver.

The use of spread sheet with Microsoft Excel ${ }^{\circledR}$ or Matlab ${ }^{\circledR}$ tools helps the students to get the analytical results.

Once the students have been used the Potential Flow Solver to obtain the dynamic forces on jacket structure, they have to

\section{a}

$\lim _{x}^{2}$

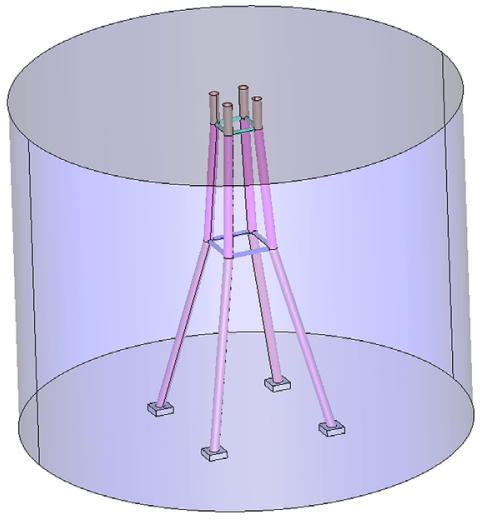

b

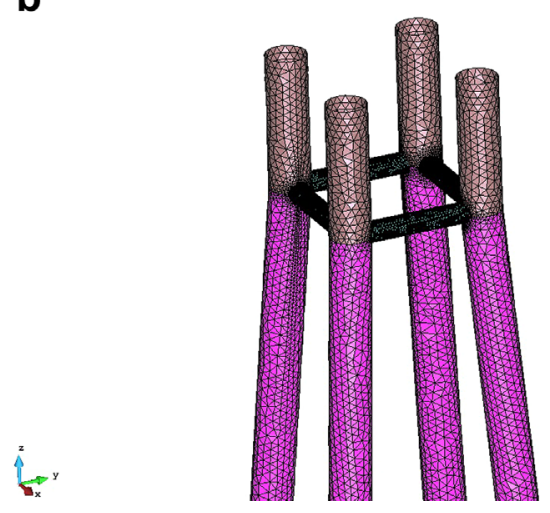

Figure 5 Jacket structure modeled using a Potential Flow Solver. (a) General morphology. (b) Detail of the generated mesh. compare the obtained results with those calculated using analytical method. The study of the discrepancies of the computed results obtaining using both methods is the main objective of this comparison (see Fig. 6).

The second sub-stage on the project-based learning consists of the hydrodynamic analysis of semi-submersible platform in seaway. This type of offshore structure can be considered as a compact structure. Assuming the linear wave theory and the steady state wave field, the interaction of the incident wave with floating unit may be derived from the superposition of the potentials of the undisturbed incident wave, the wave field radiated from the body and the diffracted wave field (see Fig. 7). The viscous forces can be neglected, in some offshore units. So, the velocity potential can be expressed as [31],

$$
\Phi=\Phi_{w}+\Phi_{\mathrm{dr}}+\sum_{j=1}^{6} \Phi_{j}
$$

where $\Phi_{w}$ is the velocity potential of the undisturbed wave field, the $\Phi_{\mathrm{dr}}$ velocity potential of the diffracted wave field and $\sum_{j=1}^{6} \Phi_{j}$ the velocity potential radiated from the harmonically oscillation of the body.

The forces on wet body may be calculated as

$$
F=\rho \int_{S} \frac{\partial \Phi}{\partial t} \boldsymbol{n} \mathrm{d} S
$$

being $\boldsymbol{n}$ a vector pointing upwards body surface, and $\mathrm{S}$ is the wet body surface.

Each student selects the place where semi-submersible platform should be in operation. Then, according to Classification Societies rules as [34] or [35], suitable environmental conditions as input of the Potential Flow Solver are selected (see Fig. 8). Finally, the students analyze the forces on wet structure and the influence of inertia forces on the design of semi-submersible platforms.

The student may identify a clear process in the use of the PFS. The process can be established as follows: 


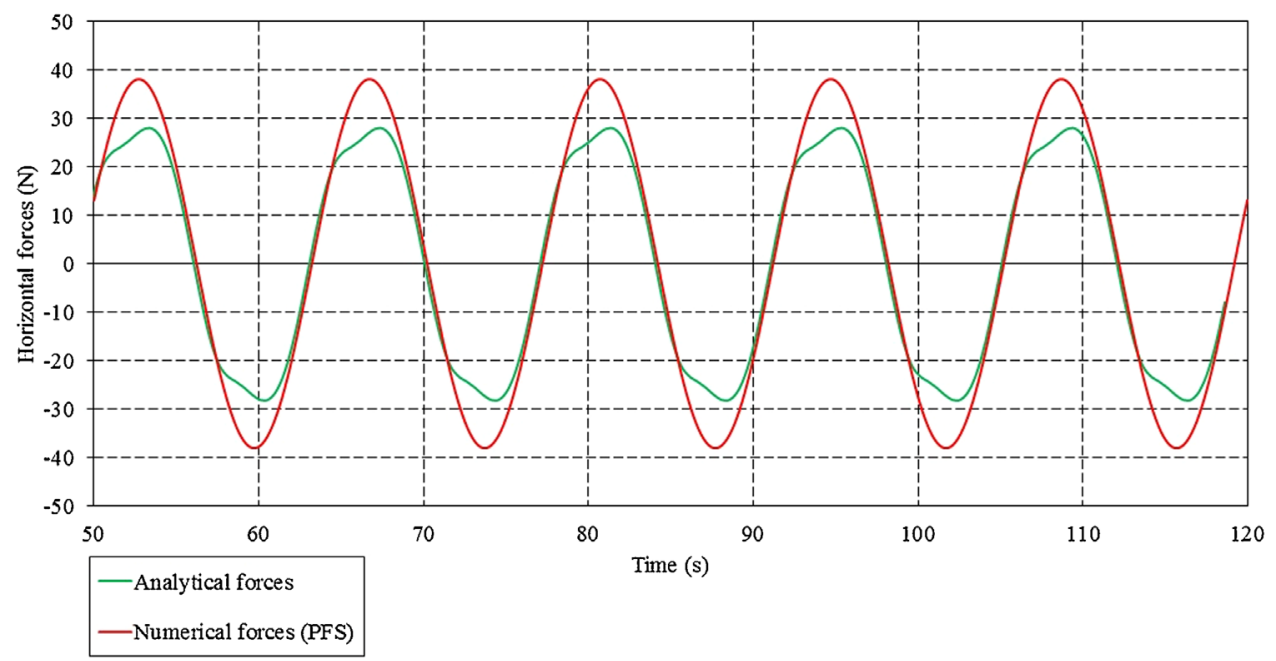

Figure 6 Comparison of the horizontal forces $\left(F_{x}\right)$ on jacket structure obtained by analytical calculation and the obtained by Potential Flow Solver tool.

- Floating unit modeling.

- Identification of the environmental condition according to the site and rules.

- Entering the suitable inputs and the boundary conditions on PFS.

- Meshing the problem to be calculated.

- Post-processing and analysis of the obtained results (see Fig. 9).

Following the previous stages, the use of video tutorials may help the student to fast acquisition of the searched skills.

\section{Third Stage}

The designer of the offshore units has to know the main functions of the platform. Depending on the assigned functions, the equipment may change substantially. Today, most of the platforms built are dedicated to Oil \& Gas, and renewable industry. So, the knowledge of the bases related to equipment and services may be an important part in the design. Main particulars of the platform can vary depending on the equipment installed [36]. For instance, if the ship-owner desires a heave lift unit, most probable design will be a semi-submersible platform. So, the center of gravity of the unit may change considerably depending on the functions itself. This fact affects directly the basic design, safety criteria, and the dynamic behavior of the unit.

This stage of learning process concerns with the acquisition of the basic skills related to the services and equipment on offshore structures. It can be said that the big offshore structures are designed to exploit the marine resources, more specifically Oil \& Gas resources. In this section, the graduates study different equipment related to Oil \& Gas industry:

- Pipe services.

- Risers.

- Umbilicals.

- Lifts.

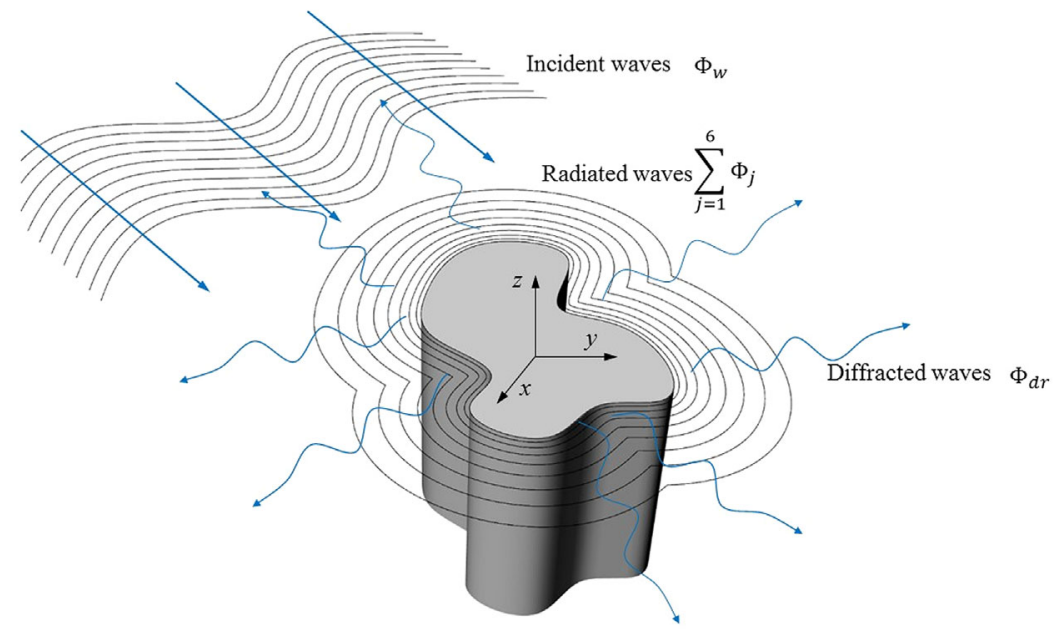

Figure 7 Assumptions used on the hydromechanical analysis of compact structures. 


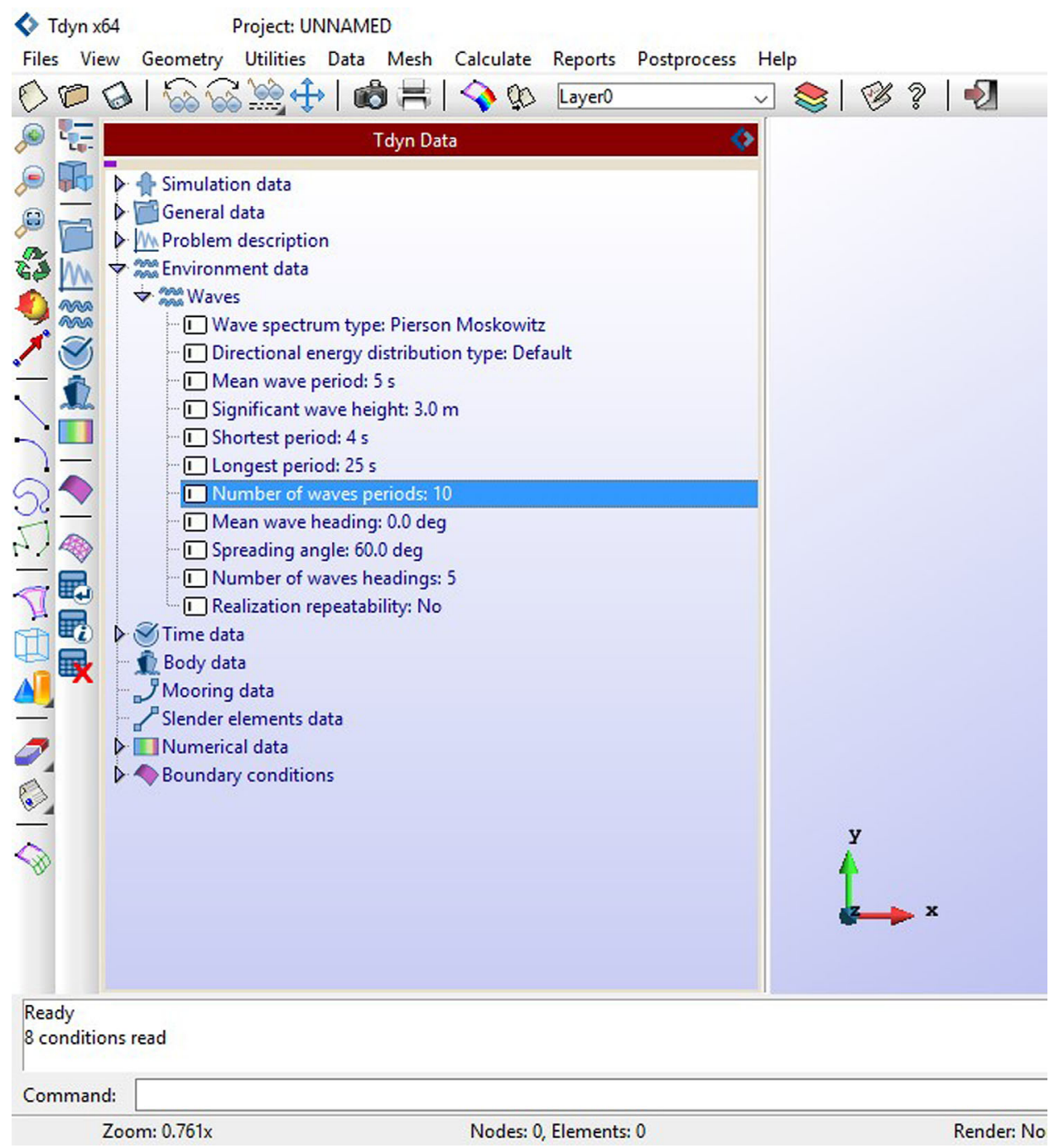

Figure 8 Data structure of the SeaFEM to enter the input values of the environmental conditions for the analysis of semisubmersible platform.

- Heave compensators: passive and active.

- Drilling equipment: lattice towers, drilling tube, drilling muds services, ...

- Living spaces.

- Gas and crude oil processing.

- Other equipment: blowout prevented, Christmas tree, ...

So, the project proposed in this step consists of the identification of the equipment of different offshore units, trying to get an approximation to center of gravity of the overall structure, using an Excel spread sheet.

\section{Fourth Stage}

The study of marine cables structures has reached great interest due to wide range of application in deep-ocean engineering. These applications include mooring line for marine structures, flexible risers, umbilical catenaries, towing hawser, subsea installations, or fishing cages composed of suspended cables subjected to marine currents [7]. Mooring structures are composed of a set of cables, chains, or wire ropes, which are attached to floating structures at different points with lower ends of these cables anchored at the seabed.

The definition and analysis of the position mooring may be considered as an important part in the design process of floating offshore units. They can be identified three methodologies to design an offshore mooring (see [37,38] rules): Static analysis, Quasi-static analysis, and Dynamic analysis.

Following the rules of Classification Societies, the mooring system shall be analyzed according to design criteria formulated in terms of three limit state equations:

- Ultimate Limit State (ULS) design.

- Fatigue Limits State (FLS) design.

- Accidental Limit State (ALS) design.

These rules [37,38], indicate that the quasi-static analysis should be usually required to determine the mooring line response subjected to mean and low frequency platform displacements, while dynamic mooring line analysis should be usually required for mooring line response to wave-frequency displacements of the platform. 

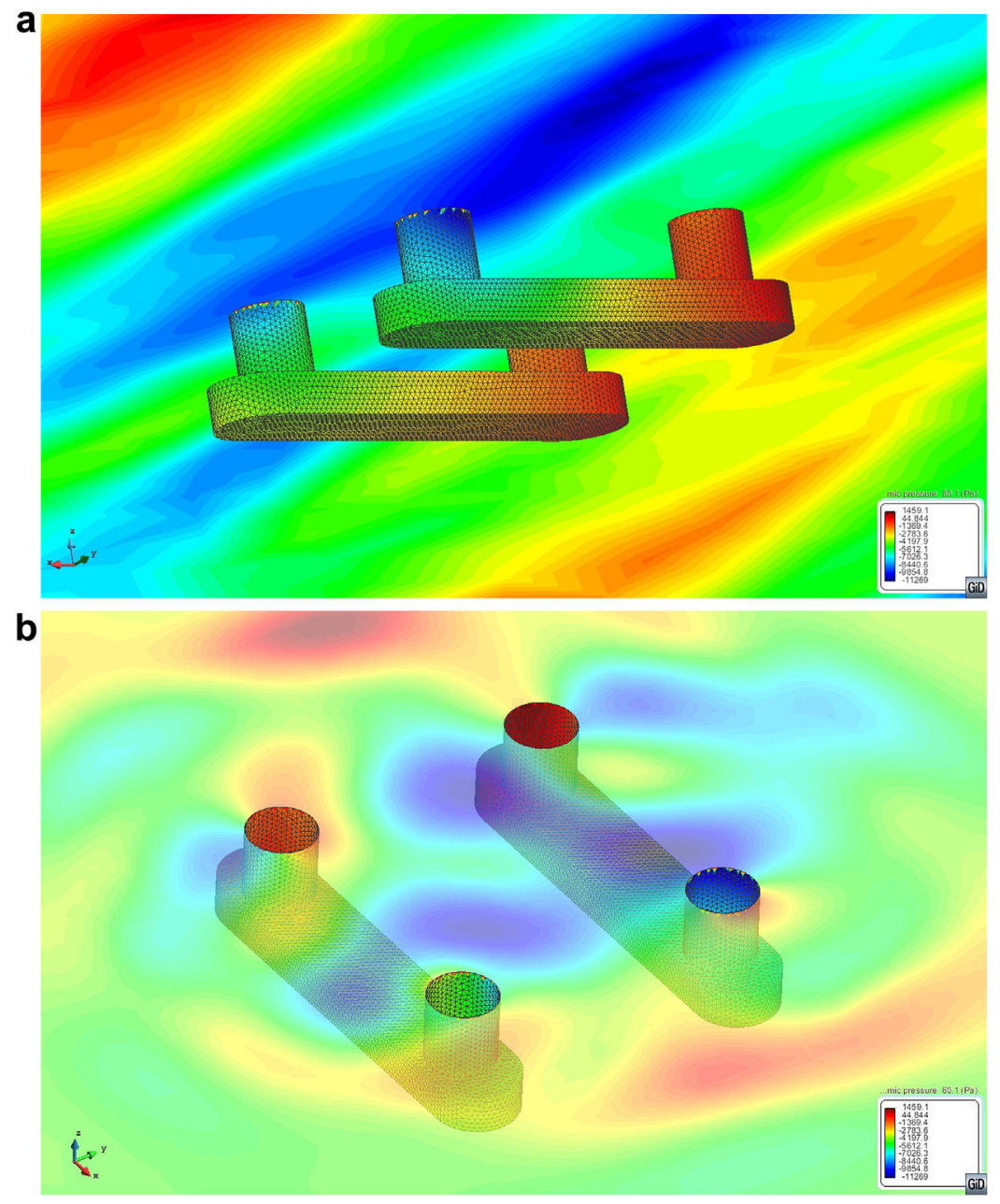

Figure 9 Results obtained in the second operational stage. (a) Caption of the pressure forces and free surface elevation on semi-submersible platform analysis using potential flow solver. (b) Caption of the pressure forces and the scattered waves of semi-submersible platform.

By using frequency domain analysis, the students design a suitable mooring arrangement for semi-submersible platform (see Fig. 10) applying ULS criteria by quasi-static analysis. It can be emphasized that the calculation of mooring system for semisubmersible involves the knowledge of some topics regarded to seakeeping study. For instance, the graduates have to be able to estimate the Response Amplitude Operator (RAO), or the standard deviation of wave and low frequency response of platform.

First of all, the students model the semi-submersible platform, according to the instruction given by the professor. By using SeaFEM, and taking into account the previous skills acquired as the creation on numerical wave tank. The process developed by graduates may be as follow:

- The modeling of semi-submersible platform.

- The creation of numerical wave tank.

- The calculation of standard deviation for wave frequency response.

- The calculation of standard deviation for low wave frequency response.

- The estimation of the mean displacement $X_{m}$ due to environmental loads.
- The calculation of significant and maximum wave and low frequency motions as [38],

$$
\begin{gathered}
X_{\mathrm{WF} \text { sig }}=2 \sigma_{\mathrm{WF}} \\
X_{\mathrm{WF} \max }=2 \sigma_{\mathrm{WF}} \sqrt{2 \ln N} \\
X_{\mathrm{LF} \mathrm{sig}}=2 \sigma_{\mathrm{LF}} \\
X_{\mathrm{LF} \mathrm{max}}=2 \sigma_{L F} \sqrt{2 \ln N}
\end{gathered}
$$

where $\sigma$ is the standard deviation of corresponding motion and $N$ is the number of platform oscillation during the calculation of environmental conditions.

- The calculation of maximum excursion of the platform in survival conditions using the values of previous step as [38] as

$$
X_{c}=X_{m}+X_{\mathrm{WF}}+X_{\mathrm{LF}}
$$

- Finally, the estimation of mooring system according with maximum excursion and breaking loads.

The explained stage involves several topics of offshore structures design. Later, as it can be observed in Figure 1, the 


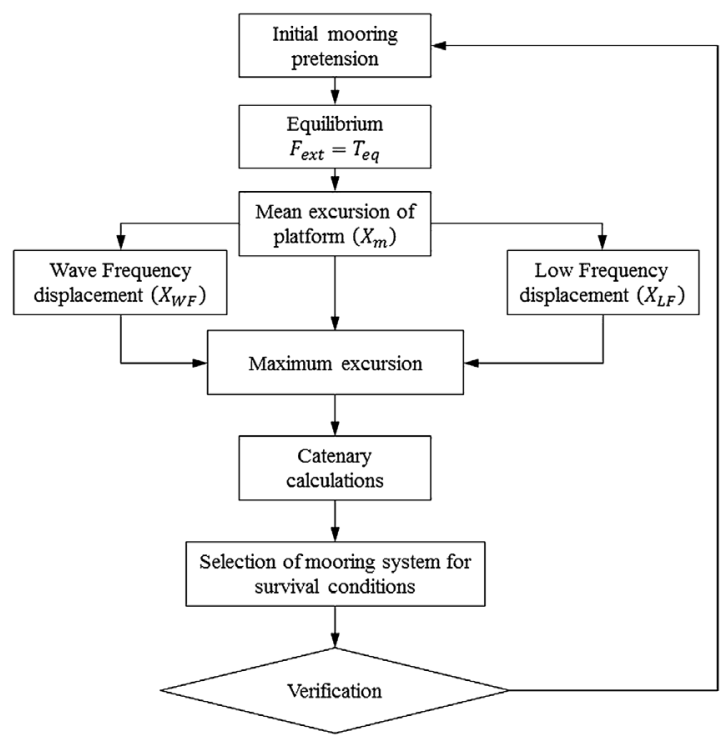

Figure 10 Scheme of the design process of mooring system by means of quasi-static procedure analysis.

students also carry out the simulation of a tension leg platform. This modeling completes the main important key aspects in mooring line analysis in offshore structures.

\section{Fifth Stage}

The final step in the Project-Based Learning process developed for the subject involves the dynamic analysis of a floating platform subject to real operational conditions. The knowledge of behavior of offshore structures may be a key in the ocean structure design.
The dynamic behavior of offshore unit has a great importance in moored structures as well as the suitable operation of the on-board equipment. The graduates use the previous modeled platform to carry out the dynamic analysis of the platform. They should introduce the main characteristics of the unit as: center of gravity, radii of gyration, previously estimated mooring lines, and metocean conditions (see Fig. 11).

The dynamics of floating platform in time domain, assuming small rotations, may be formulated as [7,22],

$$
\begin{gathered}
\mathbf{M}_{\mathbf{f}} \ddot{x}(t)=\mathbf{F}(t) \\
\overline{\mathbf{I}}_{\mathbf{f}} r \ddot{r}=\mathbf{m}(t)
\end{gathered}
$$

being $\mathbf{M}_{\mathbf{f}}$ the mass matrix of the floater, $\mathbf{F}(t)$ are the external forces acting on floater, $\overline{\mathbf{I}}_{\mathbf{f}}$ the instantaneous inertia tensor, $\mathbf{m}(t)$ are the external moments and $x$ " and $r$ the linear acceleration and angular acceleration vectors, respectively.

The student should model, simulate, visualize, and process the data obtained through the simulation of semi-submersible platform in time domain. The graduates may study the fairlead tension of mooring arrangements, the time domain response of semi-submersible as heave, surge, or pitch. Figure 12 shows heave and pitch motions for semi-submersible platform analyzed by graduates. The final stage helps the graduates to fix the skills related to the design and hydromechanical analysis of offshore units, giving a professional focus on offshore industry.

\section{ASSESMENT OF THE LEARNING PROGRESS AND STUDENT FEEDBACK}

\section{Final Grade for Students}

As explained above, the target of the present work is to facilitate the acquisition of skills concerned with offshore engineering. The subject is not easy, and therefore, the evolution of the students

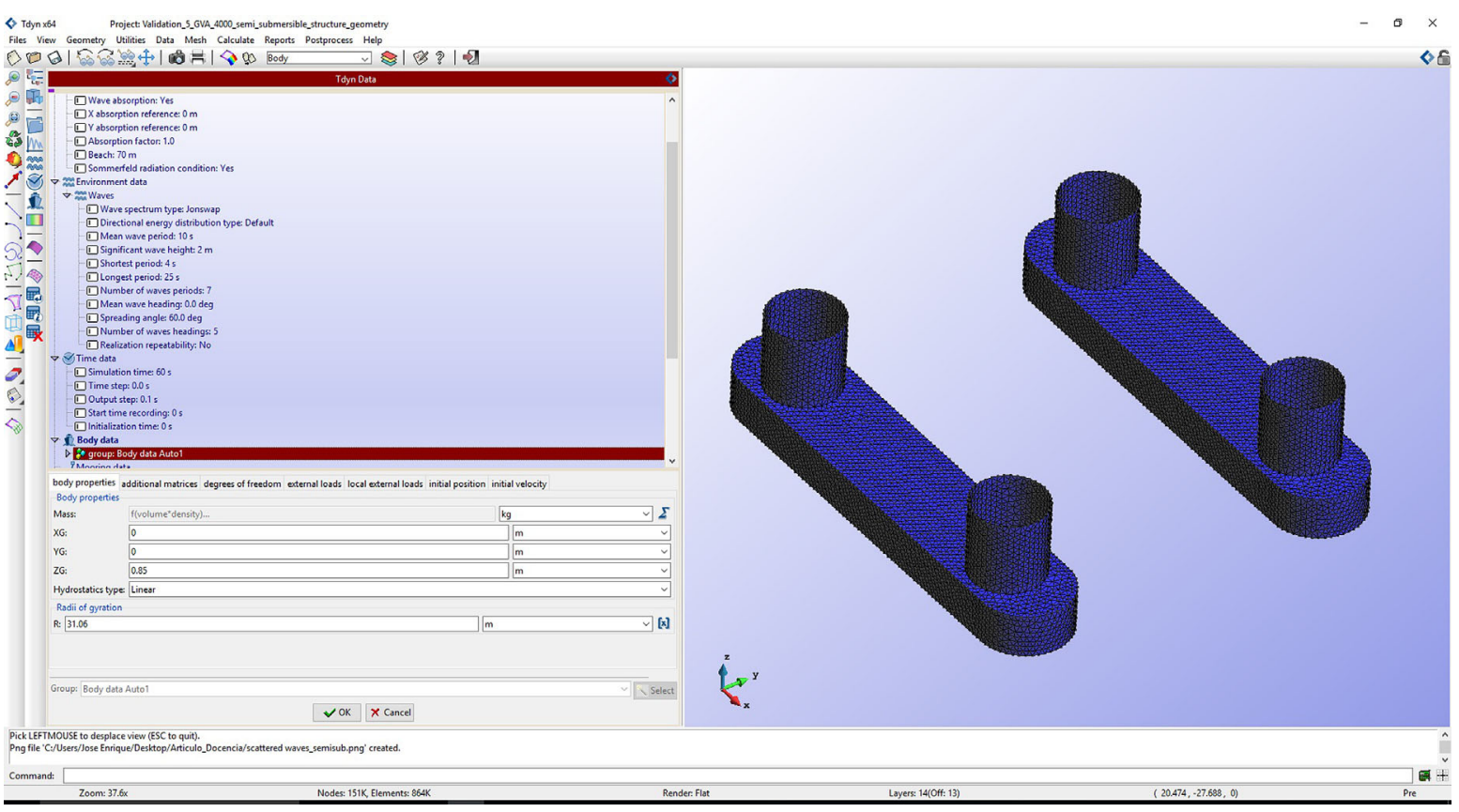

Figure 11 Some input data required to carry out the dynamic simulation of semi-submersible platform using Potential Flow Solver. 

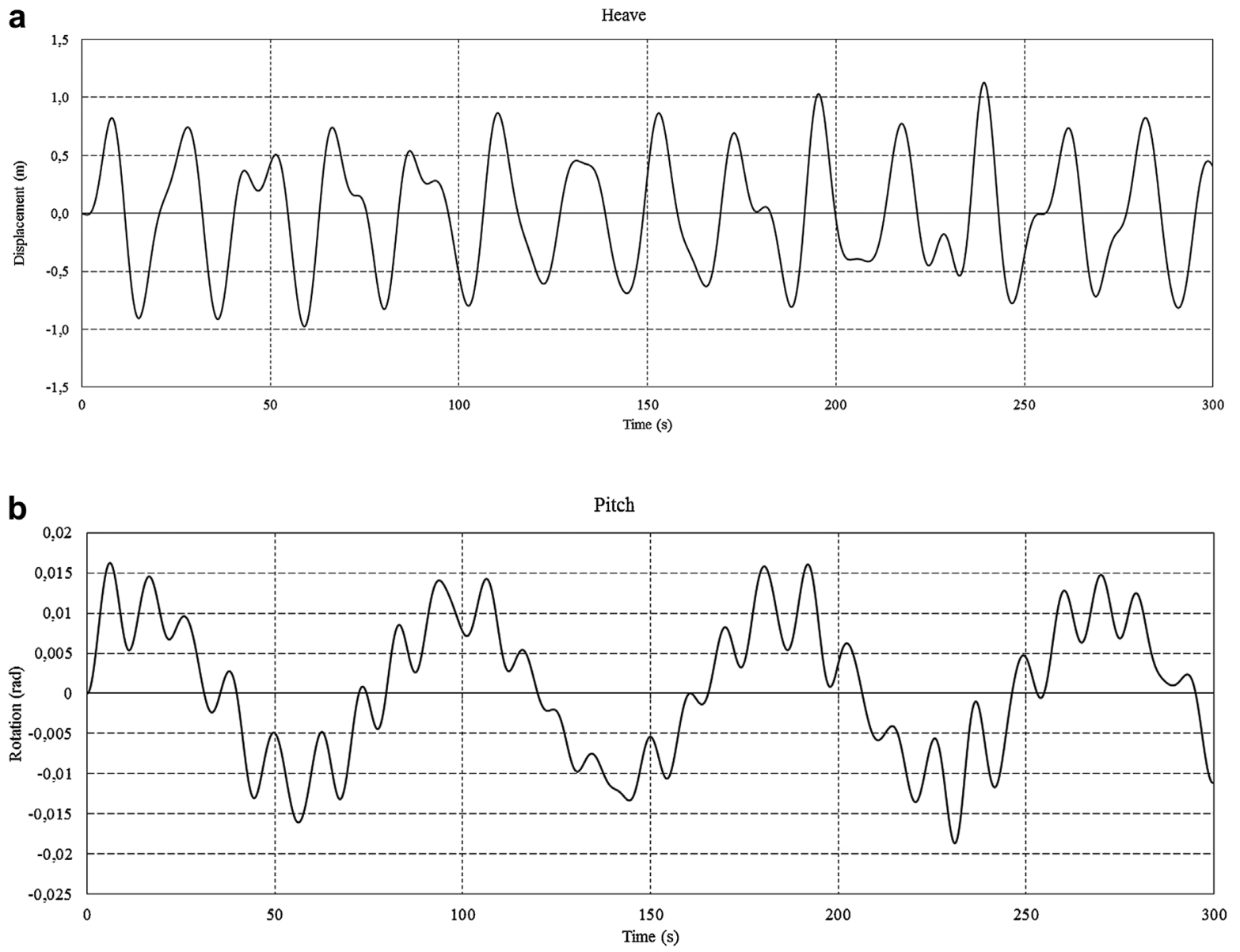

Figure 12 Representation of two typical movements of semi-submersible platform subject to irregular sea analyzed by students using Potential Flow Solver (a) Heave and (b) Pitch.

learning during the course should be assessed, as well as their overall satisfaction at the end of the course. In addition, the method for assessing the acquired knowledge by students must be in agreement with the explained teaching-learning procedure. The final grade for the students is calculated from the (weighted) contributions of four main parts:

- Grading-A: Questionnaire tests.

- Grading-B: The reports and the design calculus developed in the described five operational stages of the pedagogical method.

- Grading-C: Practical exercises and proposed forums in the classroom.

- Grading-D: The final (theoretical and practical) exam.

Following, we will describe the questionnaire tests, along with the overall assessment of the satisfaction of students at the end of the course.

\section{Learning Progress Assessment}

The assessment of the learning progress can be carried out by means of questionnaire tests (Grading- $A$ ). Each operational stage described below (five) are developed during several workshops. After the end of each stage, students should complete questionnaire tests, through the "Virtual Classroom," at the Moodle platform. In addition, two previous introductory lessons and another intermediate one are also included in the assessment. It can be inferred that, on the one hand, the learning progress of the student is evaluated and therefore this provides a useful information about the effectiveness of the implemented procedure in achieving the goals of the teaching-learning process; on the other hand, a partial mark for each student can be established for completing the final grade.

The questionnaire tests have between 10 and 20 questions depending on the considered workshop, and the students have from 20 to $60 \mathrm{~min}$ to complete (on-line) each test. In the tests, the proposed questions are concerned with the basic knowledge of each part of the course. In this manner, when the students finish each questionnaire test, some explanations about each question are shown in the Moodle platform; besides, they are explained in detail in the classroom. This leads to a better understanding of the main concepts of the subject, and contributes to better management of the provided course material. Figure 13 shows the obtained results from the questionnaire tests.

\section{Student Perceptions}

Regarding the partial marks obtained in the reports and the design calculus performed for the five operational stages above explained (Grading-B), Figure 14 shows that they are very good. This mark 


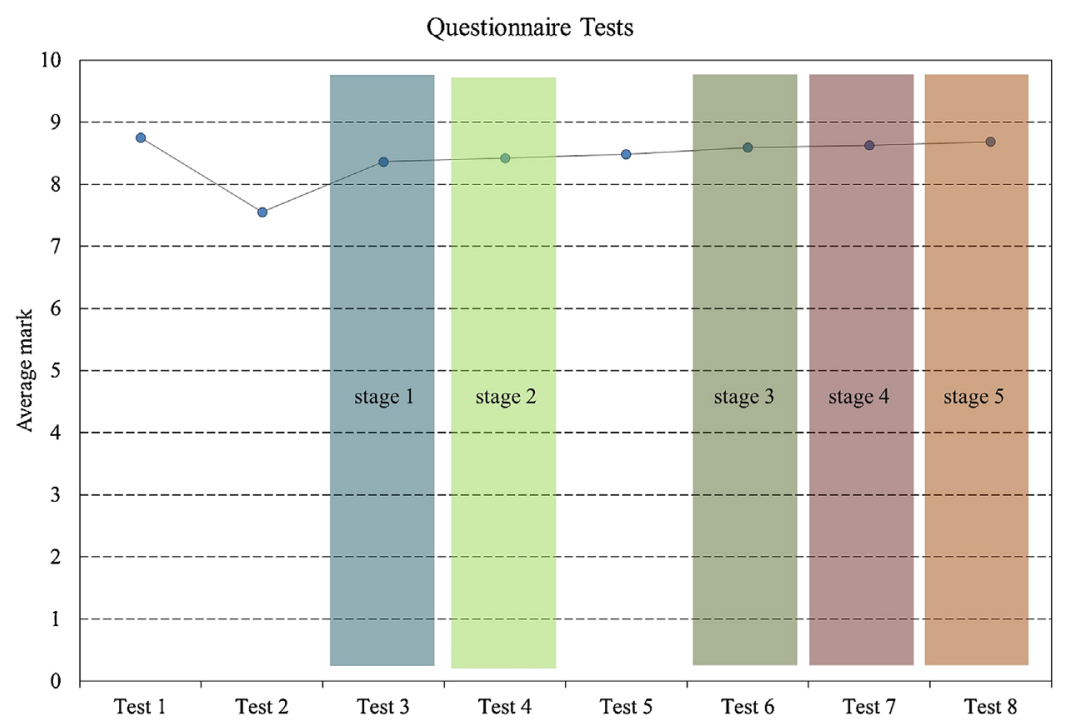

Figure 13 Average marks (10 is the maximum) obtained by students in the questionnaire tests carried out throughout the course, including the five operational stages proposed in the teaching-learning method. Assessment of the learning progress of the student, as well as the obtaining of a partial mark for completing the final grade, Grading-A.

contributes strongly to the final grade for the students. The lowest mark corresponds to the third operational stage; this can be explained by the fact that students neither use PFS nor other advanced computing tools, since this stage is concerned with the appropriate technology, finding information and so less calculation are required. In other words, this stage is concerned with the most cognitively challenging activities carried out by students during the course. Although some students indicated that this stage (and some of the others too) implied a heavy workload, they recognized that finally the overall learning was good, as well as that learning process was faster.

Moreover, the perceptions of the students can be analyzed through the problems proposed in the classroom after each part, module, or workshop. The students have to solve them in several seasons. Then, the solutions proposed by students are discussed and analyzed in class. These forums give relevant information to teacher about the effectiveness of the applied pedagogical method, provided that the collected information can interact with the method retroactively. This technique reveals that depending on the degree of interest in the module, the solutions (in general, the cases have not a single solution) given by students to the suggested problems have a variable quality level, finding that the best solutions were reached for the higher degrees of interest from students, as can be expected.

\section{Overall Satisfaction Assessment}

In order to know the overall satisfaction of the students, a questionnaire survey was conducted in the "Virtual Classroom" in the Moodle platform. This survey is completely anonymous and voluntary. The poll is divided into 13 questions related to the support given by the teacher, interactivity, acquired professional

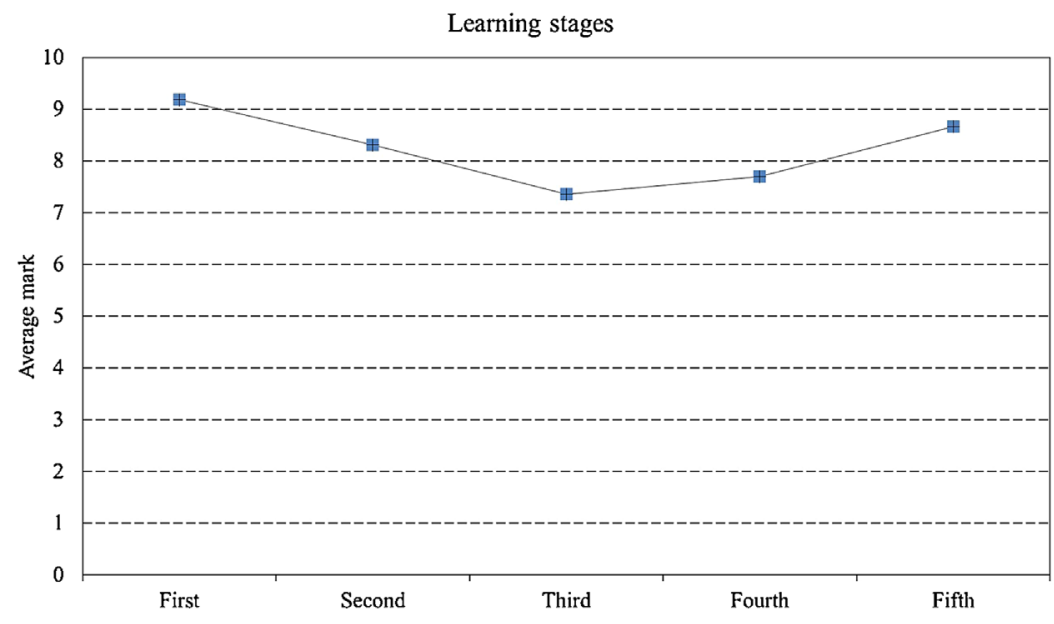

Figure 14 Average marks (10 is the maximum) obtained by students in each learning stage of the proposed procedure. Reports and design calculus, Grading-B. This mark considerably contributes to the final grade for the students. 
a

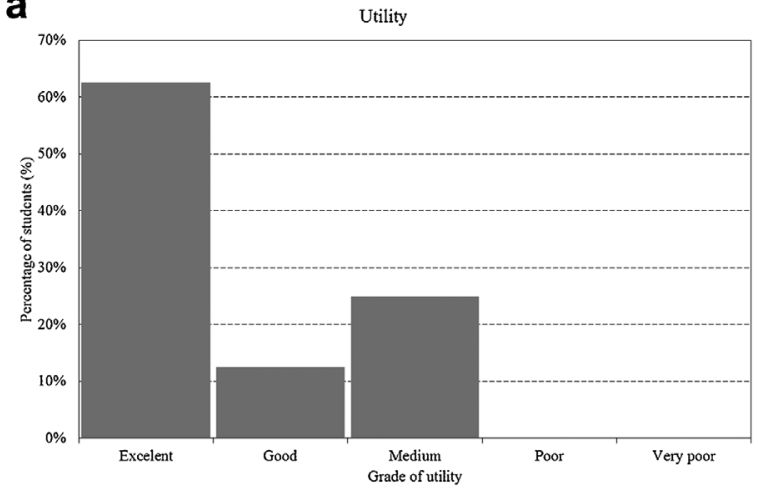

C

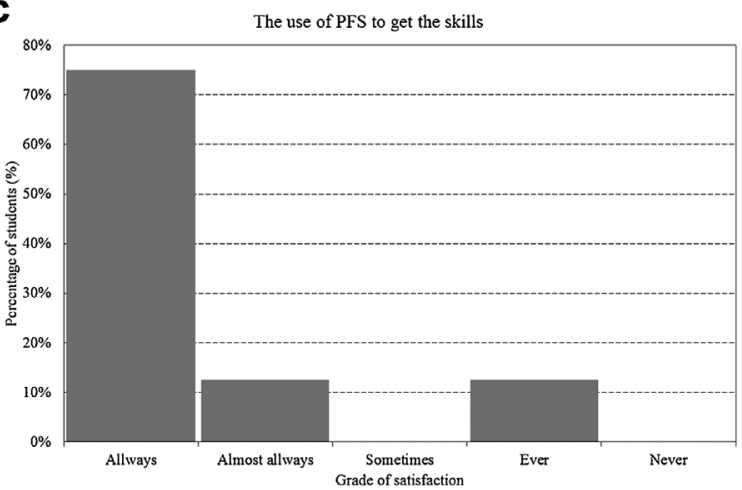

b

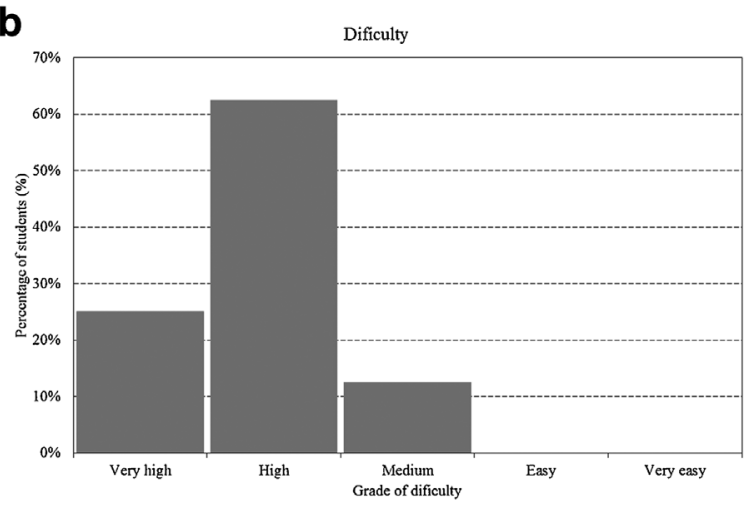

d

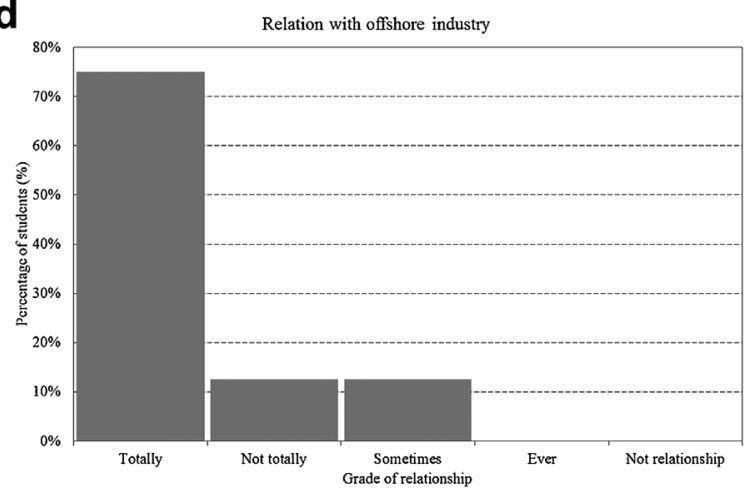

Figure 15 Assessment of the overall student satisfaction. (a) Valuation of the utility of the proposed pedagogical method. (b) Valuation of the difficulty of the method. (c) Valuation of the use of Potential Flow Solver (PFS). (d) Valuation of the relationship with the actual offshore industry.

skills, utility, and difficulty of the subject, or the employed working time (in sum, the overall opinion about the pedagogical method is being searched).

Four aspects are selected to show the more relevant results: utility and difficulty of the subject, the opinion about the use of Potential Flow Solver to acquire the skills, and the relation of the acquired skills with the offshore industry (see Fig. 15). The feedback reveals that students value the advantages of the proposed methodology. More than $80 \%$ of graduates remark the high utility of the subject. In spite of its difficulty, the majority of students value the procedure applied. More than $80 \%$ of student are also satisfied with the use of the Potential Flow Solver as a manner to acquire the basic skills related to offshore topics. In addition, more than $70 \%$ of students think that the learned skills are related to the actual offshore industry.

Summarily, from the results obtained through all the satisfaction surveys, at least $90 \%$ of graduates considered that this methodology had contributed to open fields in research and development in the regarded subject and connected with their expected professional practice.

\section{CONCLUDING REMARKS}

This paper shows how the Project Based Learning approach assisted with CFD techniques may improve the teaching-learning processes on Offshore Engineering Design courses. Special attention has been given to the acquisition of the specific engineering skills concerning with the design, analysis, and evaluation of the performance of offshore units.

The applied approach contributes to avoid the epistemological obstacles that are often detected among the students, helping them to rapid acquisition of expected skills. Furthermore, more than $80 \%$ of students who have been consulted, declared that the developed pedagogical method is suitable and useful, helping the graduates to the understanding of the issues related to offshore design. As observed in the student satisfaction assessment, most of students think that the employed methodology has a closer connection to industry environments. So, this method has increased the satisfaction of the students in a significant way, and opens their fields in research and development on offshore engineering.

It can be stated that the main objective of the presented learning procedure is to help the student to acquire several skills in connection with offshore design. The combination of a Potential Flow Solver (PFS) combined with Information and Communication Technologies (ICT) tool is revealed as a satisfactory support to learning in Offshore Engineering Design courses.

Finally, the presented procedure may promote the interest of the graduates in the investigation and study of particular situations of offshore structures or the performance evaluation of special structures in offshore design, as offshore wind turbines. For instance, a future research to be conducted by students could be the study of the influence of different metocean conditions on the gap in semi-submersible platform and its influence on structural requirements. 


\section{REFERENCES}

[1] F. J. Velasco, E. Revestido, E. Moyano, and E. López, Remote laboratory for marine vehicles experimentation, Comput Appl Eng Educ 20 (2012), 728-740.

[2] V. Bertram and M. Peric, Advanced simulations for offshore industry applications, V. Bertram (Ed.). In: Proceedings of 12th International Conference on Computer and IT Applications in the Maritime Industries, Cortona, Hamburg (Germany), 2013, pp 7-20.

[3] Y. A.Çengel and J. M. Cimbala, Fluid mechanics (fundamentals and applications), Chapter 15, McGraw-Hill, New York, 2006.

[4] B. Zamora, A. S. Kaiser, and P. G. Vicente, Improvement in learning on fluid mechanics and heat transfer courses using computational fluid dynamics, Int J Mech Eng Educ 38 (2010), 147-166.

[5] J. E. Choi, K. S. Min, and H. W. Seo, Resistance and propulsion characteristics of various commercial ships based on CFD results, Ocean Eng 37 (2010), 549-566.

[6] F. Ruggeri, M. C. Nogueira, C. M. P. Sampaio, and K. Nishimoto, Parametric model and CFD integrated process for WED optimization, V. Bertram (Ed.). In: Proceedings of the 11th International Conference on Computer and IT Applications in the Maritime Industries, Liège, Belgium, 2012, pp 323-335.

[7] J. E. Gutiérrez-Romero, J. García-Espinosa, B. Serván-Camas, and B. Zamora-Parra, Non-linear dynamic analysis of the response of moored floating structures, Mar Struct 49 (2016), 116-137.

[8] J. Tu, G. H. Yeoh, and C. Liu, Computational fluid dynamics: A practical approach, Elsevier, Boston, USA, 2008.

[9] J. E. Gutiérrez and B. Zamora, Improving teaching-learning process through ICT methods assisted with CFD techniques for marine engineering courses, Comput Appl Eng Educ 23 (2015), 239-249.

[10] V. Terzis and A. A. Economides, The acceptance and use of computer based assessment, Comput Educ 56 (2011), 1032-1044.

[11] R. A. Pieritz, R. Mendes, R. F. A. F. Da Silva, and C. R. Maliska, CFD studio: An educational software package for CFD analysis and design, Comput Appl Eng Educ 12 (2004), 20-30.

[12] T. C. Hung, S. K. Wang, S. W. Tai, and C. T. Hung, An innovative improvement of engineering learning system using computational fluid dynamics concept, Comput Appl Eng Educ 13 (2005), 306-315.

[13] J. L. Vicéns and B. Zamora, A teaching-learning method based on CFD assisted with MATLAB programming for hydraulic machinery courses, Comput Appl Eng Educ 22 (2014), 630-638.

[14] C. G. Panagiotopoulos and G. D. Manolis, A web-based educational software for structural dynamics, Comput Appl Eng Educ 24 (2016), 599-614.

[15] V. Mutu and O. Ionas, Computer applications and technologies at ship design group galati, V. Bertram and M. Armada (Eds.). In: Proceedings of the 3rd International Conference on Computer and IT Applications in the Maritime Industries, Sigüeza, Spain, 2004, pp 334-339.

[16] F. X. Dumez, C. Chenglan, S. Boiteau, C. Kammerer, E. Mogicato, T. Dupau, and V. Bertram, A tool for rapid ship hull modelling and mesh generation, V. Bertram and P. Rigo (Eds.). In: Proceedings of the 7th International Conference on Computer and IT Applications in the Maritime Industries, Liège, Belgium, 2008, pp 6-18.
[17] J. A. Orosa, Programming languages for marine engineers, Comput Appl Eng Educ 19 (2011), 591-597.

[18] J. A. Orosa, Computer software for reducing the learning time of marine engineers, Comput Appl Eng Educ 19 (2011), 647-650.

[19] TechSmith Corporation, Camtasia Studio Software, Web site: http:// www.techsmith.com/camtasia.html

[20] J. Mills and D. Treagust, Engineering education-Is problem-based or project-based learning the answer? Austral J Eng Educ 3 (2003), 2-16.

[21] T. Markham, J. Larmer, and J. Ravitz, Project based learning handbook, Buck Institute for Education, Novato, California, USA, 2003.

[22] Compass Ingeniería y Sistemas (CompassIS), SeaFEM Website: http://www.compassis.com/compass/es/Productos/SeaFEM

[23] C. A. Rodríguez-González and J. M. Fernández-Batanero, A review of problem-based learning applied to engineering, Int J Adv Educ Res 3 (2016), 14-31.

[24] J. Dewey, How we think, D. C. Heath, Boston, USA, 1910.

[25] D. A. Kolb, Experiential learning: Experience as the source of learning and development, Prentice-Hall, New Jersey, USA, 1984.

[26] G. Gibbs, Learning by doing: A guide to teaching and learning methods, Further Education Unit, Oxford, UK, 1988.

[27] C. Mora-Luis, A. González-Marrero, R. Carrau-Mellado, B. AñorbeDiaz, and J. Martín-Gutierrez, Problem-based learning approach in marine engineering education using mobile devices and internet tools, ASME 2014 12th Biennal Conference on Engineering Systems Design and Analysis, Copenhagen, Denmark, 2014.

[28] M. Fedila, Appropriateness of problem-based learning in maritime education and training, World Maritime University Dissertations, Paper 40, Malmö, Sweden, 2007.

[29] O. M. Faltinsen, Sea loads on ship and offshore structures, Cambridge Ocean Technology Series, Cambridge, UK, 1995.

[30] S. Chakrabarti, Handbook of offshore engineering, Vol 1, Elsevier Science, UK, 2005.

[31] C. Günter, E. Lehman, and C. Östergaard, Offshore structures (Vol. 1). Conceptual design and hydromechanics, Springer-Verlag, Germany, 2005.

[32] S. Gran, A course in ocean engineering. Developments in marine technology, Vol. 8, Elsevier Science, UK, 1992.

[33] J. R. Morison, M. P. O'Brien, J. W. Johnson, and S. A. Schaaf, The force exerted by surface wave on piles, J Pet Trans 189 (1959), 149-54.

[34] American Petroleum Institute, API RP 2MET, Derivation of Metocean Design and Operating Conditions, ISO 19901-1:2005 (Modified), Petroleum and natural gas industries-Specific requirements for offshore structures-Part 1: Metocean design and operating considerations, First Edition, 2005, Web site: http://www.api.org

[35] Det Norske Veritas-Germanischer Lloyds, DNV-RP-C205, Enviromental Conditons and Enviromental Loads, DNV-GL, Web site: http://rules.dnvgl.com

[36] B. C. Gerwick, Construction of marine and offshore structures, 3rd ed., CRC Press, USA, 2007.

[37] American Petroleum Institute, API RP 2SK, Design and Analysis of Stationkeeping Systems for Floating Structures, Third Edition, Website: http://www.api.org

[38] Det Norske Veritas (Germanischer Lloyds, DNV-OS-E301, Position Mooring, DNV-GL, Website: http://rules.dnvgl.com 


\section{BIOGRAPHIES}

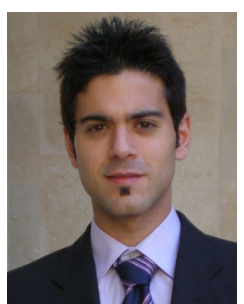

learning techniques.
José Enrique Gutiérrez-Romero was born in Mula (Spain) in 1986. He obtained his PhD in Industrial Engineering at the Technical University of Cartagena, UPCT (Spain) in 2014. $\mathrm{He}$ is lecturer of Offshore and Naval Technology in the Naval Department at UPCT. His main research areas are focused on: offshore renewable energies, mooring dynamics, ship design and Autonomous Surface Vessels. In recent years, he has been focused on teaching-

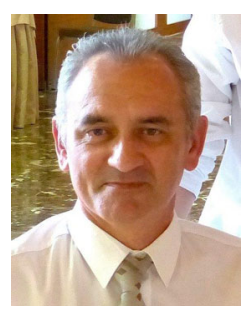

Blas Zamora-Parra was born in Mazarron (Spain) in 1968. He obtained his PhD in Industrial Engineering at the UNED University of Madrid, Spain, in 1995. He is professor of Fluid Mechanics and Hydraulic Machines at the Polytechnic University of Cartagena, Spain. His main research areas are: natural convective airflows, passive cooling of buildings (solar chimneys, Trombe walls), air-water droplets flows in cooling towers, and hydraulic machinery and hydropower. In recent years, he has been interested in the improvement of teaching-learning techniques.

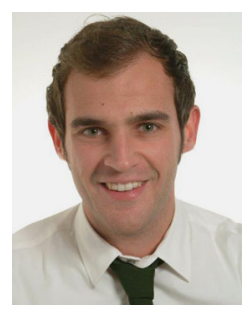

Jerónimo Esteve-Pérez was born in Elche (Spain) in 1985. He obtained his $\mathrm{PhD}$ in Business Administration and Management at the Technical University of Cartagena, UPCT (Spain) in 2015. He is assistant lecturer of Maritime Transport and Sea Trade in the Naval Department at UPCT. His main research areas are focused on: cruise ports, cruise lines market, maritime transport and Autonomous Surface teaching-learning techniques.
Vessels. In recent years, he has been focused on Vesse 